\title{
Information and communication
}

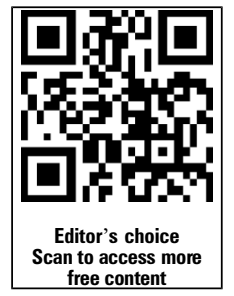

- Additional material is published online only. To view please visit the journal online (http://dx.doi.org/10.1136/ bmispcare-2013-000625).

${ }^{1}$ Academic Unit of Palliative Care, Leeds Institute of Health Sciences, University of Leeds, Leeds, West Yorkshire, UK ${ }^{2}$ Academic Unit of Psychiatry and Behavioural Sciences, Leeds Institute of Health Sciences, University of Leeds, Leeds, West Yorkshire, UK

\section{Correspondence to} Dr Matthew Allsop, Academic Unit of Palliative Care, Leeds Institute of Health Sciences, University of Leeds, Charles Thackrah Building, 101 Clarendon Road, Leeds, West Yorkshire LS2 9LJ, UK; m.j.allsop@leeds.ac.uk

Received 12 November 2013 Revised 19 December 2013 Accepted 19 January 2014 Published Online First

11 March 2014

\section{CrossMark}

\footnotetext{
To cite: Allsop MJ, Taylor S, Mulvey MR, et al. BMJ Supportive \& Palliative Care 2015:5:481-489.
}

\section{technology for managing pain in palliative care: a review of the literature}

\author{
Matthew J Allsop, ${ }^{1}$ Sally Taylor, ${ }^{1}$ Matthew R Mulvey, ${ }^{1}$ Michael I Bennett, ${ }^{1}$ \\ Bridgette M Bewick ${ }^{2}$
}

\section{ABSTRACT}

Background Information and communication technology (ICT) systems are being developed for electronic symptom reporting across different stages of the cancer trajectory with research in palliative care at an early stage.

Aim/design This paper presents the first systematic search of the literature to review existing ICT systems intended to support management of pain in palliative care patients with cancer. The review was conducted according to Preferred Reporting Items for Systematic Reviews and Meta-Analyses (PRISMA) guidelines for systematic reviews and metaanalyses.

Data sources Four databases (Embase, MEDLINE, PsycINFO and Healthcare Management Information Consortium) from 1990 to

December 2012 were searched, with exclusion of papers based on their description of ICT systems and language used.

Results 24 articles met the inclusion criteria, many of which reported the use of nonexperimental research designs. Studies were identified at different stages of development with no systems having reached implementation. Most systems captured pain as part of quality-oflife measurement with wide variation in approaches to pain assessment.

Conclusions ICT systems for symptom reporting are emerging in the palliative care context. Future development of ICT systems need to increase the quality and scale of development work, consider how recommendations for pain measurement can be integrated and explore how to effectively use system feedback with patients.

\section{INTRODUCTION}

Information and communication technology (ICT) includes all digital technologies that facilitate the electronic capture, processing, storage and exchange of information. ${ }^{1}$ The application of ICT in healthcare settings in the UK has been highlighted as a means of improving patient outcomes ${ }^{2}$ and ensuring that patients receive high-quality care. ${ }^{3}$ Electronic systems have been developed that use ICT to facilitate the capture of clinical data directly from patients, with early indications of patient acceptance of this approach. ${ }^{4}$

While systems are being developed to support different stages of the illness trajectory in cancer, the use of ICT to capture clinical data specifically in palliative care is at an early stage. ${ }^{5}$ Patients engaged with palliative care experience multiple physical symptoms, ${ }^{6}$ which affect their quality-of-life and psychological well-being. ${ }^{7}$ Pain is reported by $64 \%$ of patients with advanced cancer, ${ }^{6} 8$ but undertreatment is common. ${ }^{9}$ Frequently cited barriers to adequate pain management include knowledge deficits, inadequate pain assessment and misconceptions regarding pain. ${ }^{10}$ The use of ICT could be seen as an approach to address pain management barriers by facilitating greater communication between patients and health professionals contributing to the delivery of palliative care. ${ }^{11}$ There is scope for the development and implementation of online palliative care symptom reporting systems in which such timeliness and methods of communication can be explored, with exciting opportunities for future development. ${ }^{12}$

This paper presents a systematic search of the literature to review existing ICT systems intended to support management 
of pain in palliative care patients with cancer. The identification of implemented systems or those under development to support pain reporting by palliative care patients will indicate the status of system development at present and inform future work to improve palliative pain management using ICT systems. Rather than seeking to review the benefits of ICT systems and the quality of their effectiveness on implementation, this paper seeks to outline their structure. Palliative care has been acknowledged as posing its own specific challenges to systematic review methods, with an evidence base largely unsuitable for traditional forms of review and synthesis. ${ }^{13}$ The approach taken by the current review is to better understand the types of available systems through a descriptive analysis, rather than providing an assessment of the levels of quality or bias of available evidence.

\section{METHOD}

A systematic review of qualitative and quantitative literature was undertaken to identify the function and structure of existing ICT systems used in the management of pain in palliative care patients. This review takes a broad search of ICT systems used in patients with cancer with interpretation of findings orientated towards understanding the use of ICT systems in palliative care. The review was undertaken in five stages: (1) development of search strategy; (2) generation of inclusion and exclusion criteria; (3) assessment of relevance; (4) data extraction and tabulation; and (5) overview of system characteristics and descriptive analysis.

\section{Search strategy}

The search strategy was compiled to identify published reports of ICT systems for pain management. $\mathrm{MeSH}$ headings and keywords were identified (as outlined in online supplementary appendix A) and relevant databases were selected and searched in consultation with a healthcare information specialist based at the University of Leeds. The databases Embase, MEDLINE, PsycINFO and Healthcare Management Information Consortium were searched for literature published between 1990 and December 2012. The following journals were hand searched for relevant articles: Journal of Pain and Symptom Management, Supportive Care in Cancer, European Journal of Pain and BMJ Supportive \& Palliative Care. Potentially relevant references from bibliographies and citation indices were identified and abstracts assessed against selection criteria. The literature search was carried out during December 2012.

\section{Inclusion and exclusion criteria}

Inclusion criteria were developed through consensus by the research team. To be included articles had to describe the use of ICT in the management of pain in patients with cancer. The term ICT was chosen intentionally as a broad term applying to a wide range of technology use in healthcare to allow capture of existing systems documented in published literature. Management in the current search refers to the identification, assessment or monitoring of pain in patients with cancer. To be considered a management tool, the ICT system must capture information generated by patients, which is shared, reviewed or assessed by a health professional.

Papers were excluded that (i) provide no description of system structure and content; (ii) describe systems that were not designed for, or used by, patients with cancer pain; and (iii) discuss cancer pain, but not involving the use of ICT in pain management. Due to resource limits, it was intended that non-English articles be removed during the assessment of article relevance.

\section{Study selection}

Titles and abstracts were screened for relevant articles, for which full-text reports were sought. Full-text reports were assessed against the inclusion/exclusion criteria to identify eligible reports for the descriptive analysis. Details of the study identification and selection process are shown in the flowchart in figure 1, developed using Preferred Reporting Items for Systematic Reviews and Meta-Analyses guidelines. ${ }^{14}$

\section{Data extraction, appraisal and synthesis}

Data were extracted by MJA (lead author) into a tabulated form (see online supplementary appendix B) and checked by a second reviewer. Data were extracted from full-text reports meeting the inclusion criteria. To describe the stage of system development, the human-centred systems development methodology ${ }^{15}$ was used for categorising identified studies. This methodology comprises (i) planning and project selection, (ii) analysis, (iii) design and (iv) implementation. Planning and project selection refers to defining the problem and considering possible solutions. Analysis relates to examination of patient expectations and requirements for a proposed system, including early usability work. The design stage involves testing systems with patients and evaluating ease of use and preferences for layout. The implementation stage refers to an evaluative component of development and as such is referred to as the evaluation stage in the article, which includes pilot studies using a system in clinical practice (eg, in cancer centres) and summative evaluations of patient experience of using systems as part of their care.

\section{RESULTS}

The search identified 1898 citations initially, of which 24 articles met the inclusion criteria (see figure 1). A large proportion of studies were rejected following title and abstract screening $(n=1456)$. As shown in figure 1, several full-text sources $(n=76)$ were 


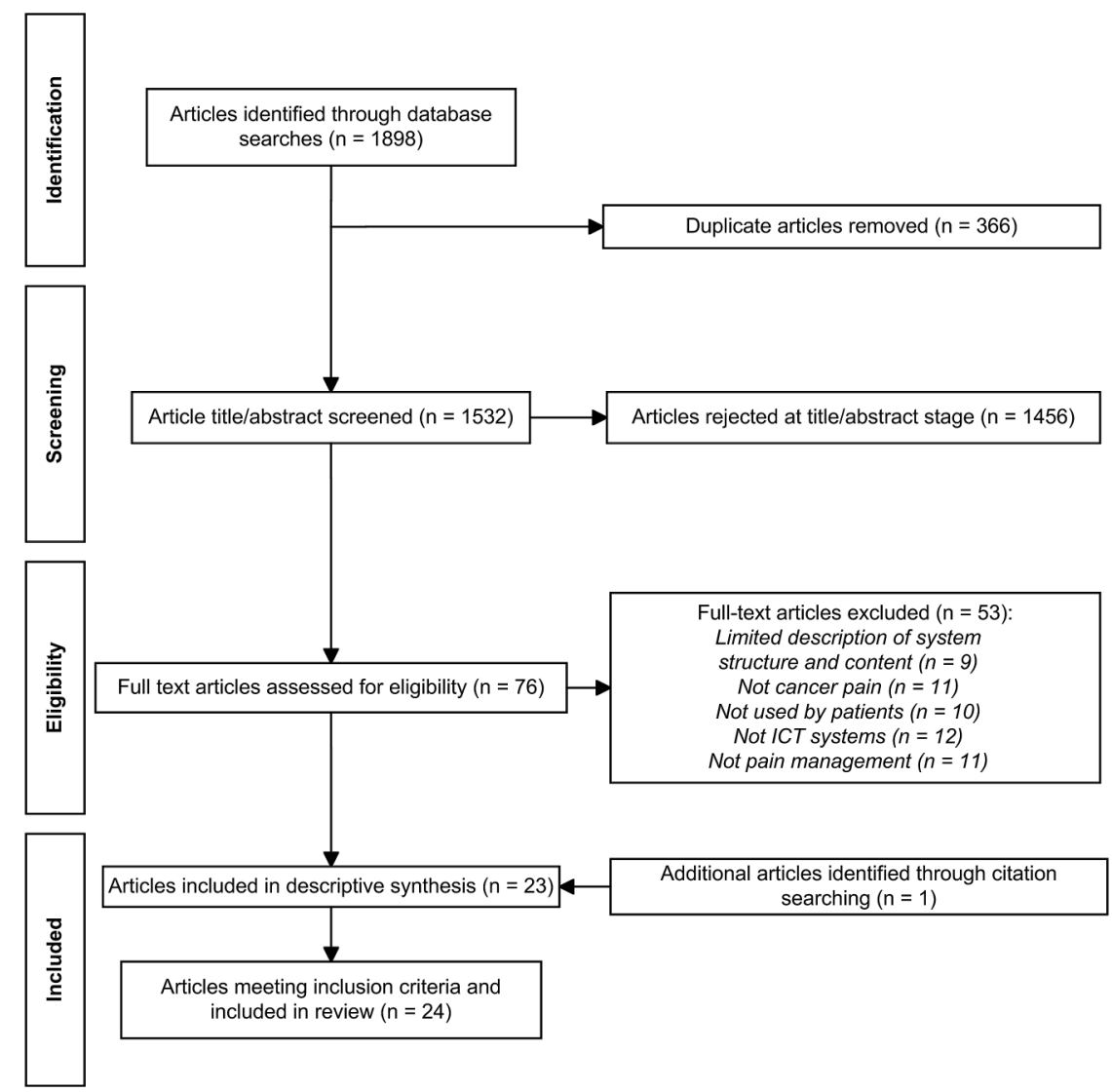

Figure 1 Preferred Reporting Items for Systematic Reviews and Meta-Analyses flow diagram of articles identified for use in the review.

examined, from which $\mathrm{n}=53$ studies were excluded. Reasons for exclusion of full-text sources included not focusing on cancer pain, discussion of systems that were not designed for communication of pain data (eg, virtual reality simulators) and systems that did not involve any interaction with a patient. Our assessment of titles and abstracts identified no non-English papers that met the inclusion criteria. Online supplementary appendix B contains an overview of all included papers and outlines the various ICT systems described. The descriptive analysis of included articles is organised into three categories: (i) study design, location and population; (ii) system design and development; and (iii) communication facilitation.

\section{Study design, location and population}

Study design

Of the 24 included studies, 7 unique study designs were described: randomised experiment, ${ }^{16-19}$ nonrandomised experiment, ${ }^{5}$ observational, ${ }^{20}$ survey design, ${ }^{21} 22$ system description, ${ }^{23} 24$ expert opinion ${ }^{25}$ and a non-specified non-experimental study design. ${ }^{26-38}$ The largest proportion of included papers used a nonspecified non-experimental study design, ${ }^{34-46}$ including reports of patients completing usability evaluations or providing feedback on specific system features using a range of methods including qualitative interviews and descriptive evaluation.

Location of system

Of the 24 included studies, 17 independent systems were identified. As shown in table 1, the majority of systems $(n=10)$ were identified from research that was conducted in the USA. ${ }^{16-19} \quad 22-24 \quad 26-28 \quad 30 \quad 31 \quad 36-38$ Other countries in which systems were identified include Sweden, ${ }^{33-35}$ the $\mathrm{UK}^{25}{ }^{25}{ }^{32}$ Austria, ${ }^{20}$ Germany, ${ }^{21}$ Japan $^{29}$ and Norway. ${ }^{5}$

Target population for system

Of the 24 included studies, the target population or intended users of systems were oncology patients, ${ }^{18} \quad 22 \quad 26 \quad 28-30 \quad 36$ palliative home care patients, ${ }^{33-35}$ oncology outpatients, ${ }^{27} 37$ hospice and palliative care patients, ${ }^{24}{ }^{31}$ patients undergoing palliative radiotherapy, ${ }^{17}{ }^{25} \mathrm{a}$ mix of palliative care patients, carers and health professionals, ${ }^{23}$ brain tumour outpatients, ${ }^{20}$ patients requiring surgery for cancer, ${ }^{16}$ patients with cancer with incurable metastatic or locally advanced disease, ${ }^{5}$ patients receiving chemotherapy for cancer, ${ }^{32}$ breast cancer survivors, ${ }^{21}$ patients with cancer with depression and/or pain, ${ }^{19}$ and a mix of members of the public with pain and people with cancer pain. ${ }^{38}$ 
Table 1 Countries from which the identified papers originate

\begin{tabular}{|c|c|c|c|c|}
\hline Country & Reference & System name & $\begin{array}{l}\text { Number } \\
\text { of articles }\end{array}$ & $\begin{array}{l}\text { Systems } \\
\text { identified }\end{array}$ \\
\hline$\overline{U S A}$ & $\begin{array}{l}17 \\
18 \\
19 \\
22 \\
26 \\
36 \\
30\end{array}$ & $\begin{array}{l}\text { INCPAD } \\
\text { INCPAD } \\
\text { INCPAD } \\
\text { PACE System } \\
\text { PACE system } \\
\text { PACE system } \\
\text { PAINReportlt and } \\
\text { PAINConsultN } \\
\text { PAINReportlt \& } \\
\text { PAINConsultN } \\
\text { SIAM-PC } \\
\text { SymptomReport } \\
\text { and } \\
\text { SymptomConsult } \\
\text { Tell Us } \\
\text { No name } 1 \\
\text { No name } 2 \\
\text { No name } 3 \\
\text { No name } 4\end{array}$ & 15 & 10 \\
\hline Sweden & $\begin{array}{l}33 \\
34 \\
35\end{array}$ & $\begin{array}{l}\text { Anoto Technology } \\
\text { Anoto Technology } \\
\text { Anoto Technology }\end{array}$ & 3 & 1 \\
\hline UK & 32 & $\begin{array}{l}\text { HealthHUB and } \\
\text { CareHUB } \\
\text { ASyMS }\end{array}$ & 2 & 2 \\
\hline Austria & 20 & No name 6 & 1 & 1 \\
\hline Germany & 21 & No name 7 & 1 & 1 \\
\hline Japan & 29 & No name 8 & 1 & 1 \\
\hline Norway & 5 & EPCRC-CSA & 1 & 1 \\
\hline Total & & & 24 & 17 \\
\hline
\end{tabular}

INCPAD, Indiana Cancer Pain and Depression; PACE, Patient Assessment, Care and Education; SIAM-PC, System for Interactive Assessment and Management in Palliative Care.

Sample population

Fifteen of the twenty-four included studies recruited patients with cancer only. ${ }^{5} \quad 16-21 \quad 26-30 \quad 34 \quad 35 \quad 37$ The remaining articles recruited mixed groups of health professionals and patients, ${ }^{22} 3132$ health professionals only, ${ }^{33}{ }^{36}$ patients with cancer and the general public, ${ }^{16}$ and clinicians. ${ }^{25}$ In the two studies that provided overviews of new and emerging systems, no research participants were involved. ${ }^{23} 24$

\section{System design and development}

Figure 2 outlines the classification of included articles in the stages of system development. Of the 24 included studies, no papers discussed the planning stages of systems, 11 studies detail systems in the analysis stage, ${ }^{23} \quad 25-27293133-3537384$ studies described the design stage $\begin{array}{lll}16 & 2428 & \\ & & \end{array}$ evaluation stage. ${ }^{5}$ 17-20 22303236 Only two systems, from across five articles, 2226303638 are represented at more than one stage of development, classified in both analysis and evaluation stages. There are a number of systems $(n=4)$ in the evaluation category that do not have representation in earlier categories.

System focus and the measurement of pain

The focus of systems differed across the 24 included studies. Six studies documented systems that focused on the capture of pain information only, ${ }^{21} 30 \quad 33-3538$ while three systems considered the management of pain and depression together as part of a collaborative care approach. ${ }^{17-19}$ The remaining 15 studies outlined systems that considered pain amid a wider range of symptoms in the context of quality-of-life measurement. ${ }^{5} 162022-2931323637$

A variety of measures to capture pain information were incorporated into systems described in the included articles as outlined in table 2. Systems only considering pain incorporated the McGill Pain Questionnaire, $^{30}{ }^{38}$ bespoke visual analogue scales

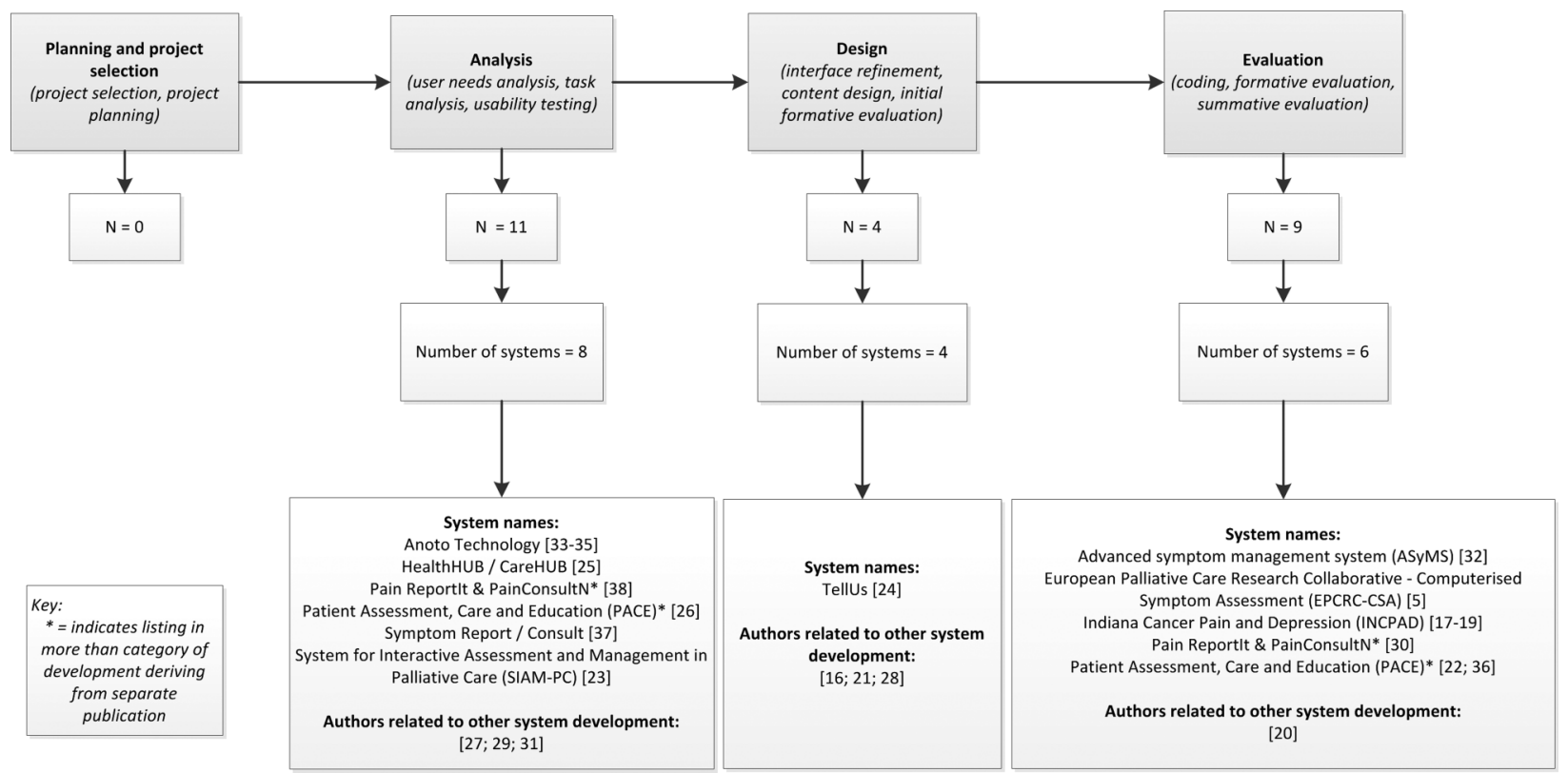

Figure 2 Stage of development for systems outlined in included articles. 
Table 2 Overview of tools used for pain measurement in the identified systems

\begin{tabular}{|c|c|c|}
\hline System focus & Reference & Measure(s) used to capture pain reports from a patient \\
\hline Pain & $\begin{array}{l}30 \\
21\end{array}$ & $\begin{array}{l}\text { Computerised extension of the MPQ } \\
\text { Areas of pain and no pain were digitised into a summation image of a female torso, with blackened areas indicating } \\
\text { pain areas and white indicating no pain } \\
\text { A pain diary form consisting of a VAS ( } 0-100 \mathrm{~mm} \text { ) for pain intensity and boxes for the number of consumed extra } \\
\text { doses of analgesics } \\
\text { Not described in paper } \\
\text { The pain diary included a unidimensional tool for assessment of pain intensity using a } 100 \mathrm{~mm} \text { VAS where the scale } \\
\text { was anchored by the words 'No pain' (VAS } 0 \mathrm{~mm} \text { ) and 'Severe pain' (VAS } 100 \mathrm{~mm} \text { ). It also included a question about } \\
\text { consumed extra doses of analgesics } \\
\text { Computerised extension of the MPQ and } 16 \text { additional items: two items related to the body outline, three } 0-10 \text { items } \\
\text { related to current pain, least pain and worst pain intensity, three items measuring goals for pain levels and amount of } \\
\text { time pain greater than tolerable level, one item measuring patient satisfaction with pain level, and one item addressing } \\
\text { a range of concepts (expectations about the pain, effectiveness of previous pain treatments, pain medication treatment } \\
\text { pattern, non-drug treatments used for pain, tendency to tell or not tell others about the pain, onset of pain and beliefs } \\
\text { about the cause of the pain) }\end{array}$ \\
\hline $\begin{array}{l}\text { Pain and } \\
\text { depression }\end{array}$ & $\begin{array}{l}19 \\
17\end{array}$ & $\begin{array}{l}7 \text { core items, } 2 \text { items from PHQ-9, average pain from BPI, single items about global improvement, medication } \\
\text { adherence, side effects and whether a call from a nurse was required. Additional BPI questions were included for } \\
\text { patients with pain, and additional PHQ-9 questions for those with depression } \\
\text { As above } \\
\text { As above }\end{array}$ \\
\hline Quality-of-life & $\begin{array}{l}25 \\
24 \\
20 \\
28 \\
29 \\
5\end{array}$ & $\begin{array}{l}86 \text { items, reflecting common cancer-related and treatment-related symptoms, including pain } \\
\text { An } 11 \text {-point (0-10) pain-intensity numerical scale as an additional item } \\
\text { Not described in paper } \\
\text { MDASI, a brief, validated measure of } 13 \text { common cancer-related symptoms over the previous } 24 \mathrm{~h} \text {. Each symptom is } \\
\text { rated on an } 11 \text {-point scale, with } 0 \text { being 'not present' and } 10 \text { being 'as bad as you can imagine' } \\
\text { ESAS to be completed daily and the EQ-5D weekly } \\
\text { Symptom-specific questions, including an } 11 \text {-point scale for reporting pain level } \\
\text { QOL assessment EORTC QLQ-C30 and the EORTC BN20 } \\
\text { EORTC QLQ-C30 } \\
\text { Intensity of symptoms (pain, fatigue, nausea, anxiety, depression and drowsiness) rated using a } 0 \text { to } 100 \text { VAS } \\
\text { ESAS, EORTC QLQ-C30, screening item about pain intensity at its worst in the last } 24 \mathrm{~h} \text { (taken from BPI), } 15 \text { items on } \\
\text { physical function, PHQ-9, two questions from the SGA, five questions related to need for assistance, patients' opinions } \\
\text { on time expenditure and preferences for computerised vs paper and pencil-based assessment, and a computerised pain } \\
\text { body map. } \\
\text { Visual display of relevant information from multiple sources can be captured including PRO assessments, patient history } \\
\text { and notes } \\
\text { Aches and pain captured as part of C-SAS } \\
\text { A patient-reported symptom severity screening scale that generates a real-time, point-of-care report. Contains } 38 \text { items } \\
\text { that produce scores for individual patient-reported problems } \\
\text { As above } \\
\text { An electronic version of the } 1970 \text { edition of the MPQ, a pain barriers questionnaire and the SCFS-6 }\end{array}$ \\
\hline
\end{tabular}

BPI, Brief Pain Inventory; C-SAS, Chemotherapy Symptom Assessment Scale; EORTC BN20, European Organisation for Research and Treatment of Cancer brain cancer module; EORTC QLQ-C30, European Organisation for Research and Treatment of Cancer Quality-of-Life Questionnaire; EQ-5D, EuroQol European Quality-of-Life-5 Dimensions; ESAS, Edmonton Symptom Assessment Scale; MDASI, M.D. Anderson Symptom Inventory; MPQ, McGill Pain Questionnaire; PHQ9, Brief Patient Health Questionnaire for depression; PRO, patient-reported outcome; SCFS-6, Schwartz cancer fatigue scale; SGA, Subjective Global Assessment of Nutritional Intake; VAS, Visual analogue scale.

asking patients to measure pain intensity ${ }^{35}$ and presentation of visual images of an affected region of the body for patients to indicate the location of pain. ${ }^{21}$ Papers outlining a system for capturing pain and depression $^{18} 19$ comprised a mix of items taken from the PHQ- $9^{39}$ depression scale, Brief Pain Inventory $(\mathrm{BPI})^{40}$ and single questions addressing medication adherence, adverse effects, global improvement and whether the patient wanted to be contacted by a nurse.

Systems measuring pain as part of a wider collection of symptoms used a variety of existing and bespoke symptom and quality-of-life measurement tools. The C-SAS ${ }^{41}$ EORTC QLQ-C30, ${ }^{42}$ EORTC BN20, ${ }^{43}$ EQ$5 \mathrm{D},{ }^{44} \mathrm{ESAS},{ }^{45} \mathrm{MDASI},{ }^{46} \mathrm{SCFS}-6,{ }^{47}$ and SGA, ${ }^{48}$ are among measures used alone or in combination with other measures in the identified systems. Systems measuring pain as part of a wider collection of symptoms also used numerical scales and five-point response items to capture pain intensity or the impact of cancer on components such as sexual interest and function. No consistency in the use of measures for capturing pain reports from patients was evident, and there was variation in the compilation and presentation of measures of pain across all systems independent of the system focus.

\section{Communication facilitation}

As shown in table 3 , of the 24 included studies, the intended location of use of systems for patients varied between waiting room $(n=12)$, home setting $(n=8)$ and remote use in the community $(n=4)$. Systems intended for use in the waiting room capture and collate information for review by a health 
professional, typically prior to consultation. Where the intended location for patients is the home setting, ${ }^{16} 2325292^{32-35}$ ICT systems add to an existing dialogue about pain or its changing nature. Systems in this category typically involve the monitoring of pain symptoms, either actively by nursing staff or through thresholds that generate alerts to health professionals when patient scores are reported outside of a predetermined acceptable range. Systems intended for remote use by patients ${ }^{17-19} 24$ provide flexibility in ways to report pain using web-based systems alongside automated or patient-initiated symptom reporting via landline or computer. One system ${ }^{24}$ was specifically designed for use with hospice and palliative care patients to accommodate a situation where patient status may change rapidly and/or need regular monitoring.

\section{System feedback}

Systems described in the included studies facilitated two forms of communication: patient to health professional $(n=15)$ (where a patient enters data that are sent directly to a health professional without receiving

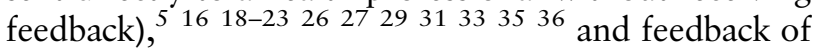
information presented to patient and health professional following patient entry of information

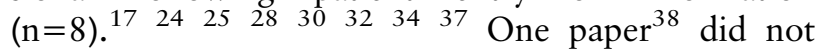
report on the feedback provided by the system.

Systems facilitating patient to health professional communication ${ }^{5} 16 \quad 18-232627293133 \quad 3536$ did not create any additional dialogue between these two groups. Systems informed or alerted health professionals to the experience of pain in a patient, which may be used to impact on decision making regarding pain management. This feedback provided only to the health professional was in the form of patient score summaries that could be printed, quality-of-life profiles showing longitudinal charts or graphical summaries for patients, and summation pictures of areas where pain is reported. The modes of technology that were used to capture data from patients for this purpose included landline and mobile telephone, and handheld devices (such as tablet computers).

Systems providing feedback to patients and health professionals $(n=8)$ provided different forms of output for each group. For patients, these systems reported one or more of the following types of feedback:

1. specific self-care advice when symptoms are reported out of a predefined range

2. graphical display of scores over time

3. tailored educational materials relating to symptoms

4. personalised feedback from a nurse (via phone or online)

A combination of these types of feedback was present in one system, ${ }^{24}$ which provided presentations of scores over time and tailored educational materials. For health professionals, the types of information provided through this category of system are similar to those providing information from a patient to a health professional only. For example, patient scores can be printed out and reviewed by a health professional or used during a consultation with a patient. Additional features were also identified in this category of systems, with the use of predefined ranges set to prompt email alerts. One system ${ }^{20}$ used the information reported by a patient to produce summaries of pain data and an evidence-based treatment plan to support clinical management decisions.

\section{DISCUSSION}

This review has found that few ICT systems for pain reporting in palliative care patients are evaluated in the context of experimental research and no systems are reported to be implemented in clinical practice. Over half of the articles reviewed describe systems that were in the early stages of design and provided little detail on the overall development approach being taken. When identifying how ICT systems facilitate pain management, it was found that most ICT systems conduct pain assessment in the context of wider quality-of-life measurement in patients with cancer. A focus only on pain symptoms was seen in a small proportion of the included ICT systems, where reports were collected directly from the patient for use by a health professional with no feedback provided to the patient. The possibilities of feedback that can be generated by ICT systems have only begun to be explored with patients and health professionals with a small number of systems.

ICT system development is an emerging area of research in healthcare that may reflect the low numbers of systems identified across the stages of

Table 3 The location for systems to be used by patients and health professionals in the identified articles (numbers correspond to study number in online supplementary appendix B)

\begin{tabular}{|c|c|c|c|c|}
\hline & & \multicolumn{3}{|l|}{ Location for patient } \\
\hline & & $\begin{array}{l}\text { Clinic waiting } \\
\text { room }\end{array}$ & $\begin{array}{l}\text { Home } \\
\text { setting }\end{array}$ & $\begin{array}{l}\text { Remote use in } \\
\text { community }\end{array}$ \\
\hline Location for Health Professional & $\begin{array}{l}\text { Clinical environment } \\
\text { Remotely (eg, web-based systems) } \\
\text { No setting defined }\end{array}$ & 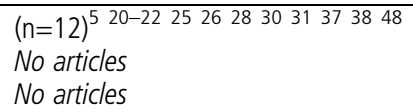 & $\begin{array}{l}(n=5)^{25} 32-35 \\
(n=2)^{1623} \\
(n=1)^{29}\end{array}$ & $\begin{array}{l}(\mathrm{n}=4)^{17-1924} \\
\text { No articles } \\
\text { No articles }\end{array}$ \\
\hline
\end{tabular}


system development. This is highlighted through the generally low quality of development research found in symptom-reporting systems. ${ }^{49}$ Concerns have been raised about the use of technologies in cancer care when implementation occurs prior to established clinical efficacy or use. ${ }^{50}$ Encouraging structured development of ICT systems with continued dissemination of findings is a strategy that can support high-quality research generation across all areas of application in healthcare.

Many systems identified in this review were designed to capture information from a patient for use by a healthcare professional in a clinical setting, with a patient relaying symptom reports without engaging in active forms of communication. Although cancer symptom reporting tends to occur inside healthcare institutions, ${ }^{51}$ the unidirectional provision of pain reports to a health professional (via ICT systems) ignores the benefits to both parties (particularly the patient) that could derive from feedback or tailored support in response to data entered into an ICT system. Although feedback was provided by some of the systems identified here, there is now a clear need for future research to explore how ICT system feedback can be used to improve pain management in palliative care.

The lack of consistency in pain measures identified in ICT systems may impact on the assessment and management of patients in palliative care. When used in palliative care, pain assessment tools can include dimensions and items of limited relevance for patients with advanced cancer. ${ }^{52}$ This can negatively influence patients, such as reducing compliance to assessment, and should be considered to ensure clinical relevance of selected tools and measures. Well-validated, multidimensional assessment tools such as the $\mathrm{BPI}^{43}$ and McGill Short Form Questionnaire $^{53}$ have been suggested for use in capturing the experience of pain. ${ }^{54}$

A descriptive analysis of the literature was chosen as a tool for understanding the current state of ICT system development in the literature to inform thinking for future areas of research and development. The scope of systems included in the review was limited to systems reported in research literature. Inclusion of systems was reliant on developers and researchers disseminating the design processes of an ICT system in the research literature. In order to counter this limitation, the search strategy was broadened to include all cancer not just advanced cancer (ie, palliative care). The strength of this is that we are likely to have broadened the search and captured a greater number of ICT systems, but not all included systems have been developed and validated in palliative sample populations that may not accurately reflected our target population (palliative care patients with advanced cancer and pain) in terms of their needs, experiences and symptom profiles.
The use of ICT systems presents an approach to improving the management of pain in palliative care patients with cancer. This is the first review of ICT systems used to manage pain in palliative care. A number of systems were identified in this systematic review of the literature, with systems focusing specifically on pain alongside those capturing more varied measures of quality-of-life. Future ICT system development needs to consider the palliative care context closely to assess how existing and emerging systems can be integrated effectively. ICT systems in palliative care need to increase the quality and scale of development work, adhere to recommended pain measure use and consider how to effectively use feedback to patients. If achieved, ICT system development in palliative care promises a platform on which patients and health professionals can engage in an efficient and meaningful dialogue to improve the management of pain.

Contributors MJA and BMB conceived the paper and generated early drafts of the paper. MJA led the reviewing process. ST, MRM and MIB contributed to the reviewing process and revised later drafts of the paper.

Funding This paper presents independent research commissioned by the National Institute for Health Research under its Programme Grants for Applied Research programme ("Improving the Management of Pain from Advanced Cancer in the Community" (IMPACCT): RP-PG-0610-10114). The views expressed in this report are those of the authors and not necessarily those of the NHS, the National Institute for Health Research or the Department of Health.

Competing interests None.

Provenance and peer review Not commissioned; externally peer reviewed.

\section{REFERENCES}

1 Gagnon MP, Desmartis M, Labrecque M, et al. Systematic review of factors influencing the adoption of information and communication technologies by healthcare professionals. J Med Sys 2012;36:241-77.

2 Liddell A, Adshead S, Burgess E. Technology in the NHS: transforming the patient's experience of care. The Kings Fund, 2008.

3 Department of Health. Equity and excellence: liberating the NHS. 2010. http://www.dh.gov.uk/en/Publicationsandstatistics/ Publications/PublicationsPolicyAndGuidance/DH_117353 (accessed 10 Jan 2012).

4 Johansen MA, Berntsen G, Shrestha N, et al. An exploratory study of patient attitudes towards symptom reporting in a primary care setting: benefits for medical consultation and syndromic surveillance? Methods Inf Med 2011;5:479-86.

5 Hjermstad MJ, Lie HC, Caraceni A, et al. Computer-based symptom assessment is feasible in patients with advanced cancer: results from an international multicenter study, the EPCRC-CSA. J Pain Symptom Manage 2012;44:639-54.

6 Kirkova J, Rybicki L, Walsh D, et al. Symptom prevalence in advanced cancer: age, gender, and performance status interactions. Am J Hosp Palliat Care 2012;29:139-45.

7 Cleeland CS. Symptom burden: multiple symptoms and their impact as patient-reported outcomes. J Natl Cancer Inst Monogr 2007;37:16-21. 
8 van den Beuken-van Everdingen MH, de Rijke JM, Kessels AG, et al. Prevalence of pain in patients with cancer: a systematic review of the past 40 years. Ann Oncol 2007;18:1437-49.

9 Bennett MI, Graham J, Schmidt-Hansen M, et al. Prescribing strong opioids for pain in adult palliative care: summary of NICE guidance. BMJ 2012;344:e2806.

10 Oldenmenger WH, Sillevis Smitt PA, van Dooren S, et al. A systematic review on barriers hindering adequate cancer pain management and interventions to reduce them: a critical appraisal. Eur J Cancer 2009;45:1370-80.

11 Dempster PG, Bewick BM, Jones R, et al. Management of cancer pain in the community: perceptions of current UK information technology systems and implications for future development. Health Informatics J 2012;18:284.

12 Kreps G. Communication and palliative care: $e$-health interventions and pain management. New York: Springer, 2012.

13 Gardiner C, Ingleton C, Gott M, et al. Exploring the transition from curative care to palliative care: a systematic review of the literature. BMJ Support Palliat Care 2011;1:56-63.

14 Liberati A, Altman DG, Tetzlaff J, et al. The PRISMA statement for reporting systematic reviews and meta-analyses of studies that evaluate healthcare interventions: explanation and elaboration. BMJ 2009;339:b2700.

15 Zhang P, Carey J, Te'eni D, et al. Integrating human-computer interaction development into the systems development life cycle: a methodology. Commun Assoc Info Syst 2005;15:512-43.

16 Cleeland CS, Wang XS, Shi Q, et al. Automated symptom alerts reduce postoperative symptom severity after cancer surgery: a randomized controlled clinical trial. J Clin Oncol 2011;29:994-1000.

17 Johns SA, Kroenke K, Theobald DE, et al. Telecare management of pain and depression in patients with cancer: patient satisfaction and predictors of use. J Ambul Care Manage 2011;34:126-39.

18 Kroenke K, Theobald D, Norton K, et al. The Indiana Cancer Pain and Depression (INCPAD) trial Design of a telecare management intervention for cancer-related symptoms and baseline characteristics of study participants. Gen Hosp Psychiatry 2009;31:240-53.

19 Kroenke K, Theobald D, Wu J, et al. Effect of telecare management on pain and depression in patients with cancer: a randomized trial. JAMA 2010;304:163-71.

20 Erharter A, Giesinger J, Kemmler G, et al. Implementation of computer-based quality-of-life monitoring in brain tumor outpatients in routine clinical practice. J Pain Symptom Manage 2010;39:219-29.

21 Jud SM, Fasching PA, Maihöfner C, et al. Pain perception and detailed visual pain mapping in breast cancer survivors. Breast Cancer Res Treat 2010;119:105-10.

22 Mark TL, Fortner B, Johnson G. Evaluation of a tablet PC technology to screen and educate oncology patients. Support Care Cancer 2008;16:371-78.

23 Chang CH, Boni-Saenz AA, Durazo-Arvizu RA, et al. A system for interactive assessment and management in palliative care. J Pain Symptom Manage 2007;33:745-55.

24 Dy SM, Roy J, Ott GE, et al. Tell Us: a Web-based tool for improving communication among patients, families, and providers in hospice and palliative care through systematic data specification, collection, and use. J Pain Symptom Manage 2011;42:526-34.

25 Cox A, Illsley M, Knibb W, et al. The acceptability of e-technology to monitor and assess patient symptoms following palliative radiotherapy for lung cancer. Palliat Med 2011;25:675-81.

26 Abernethy AP, Herndon JE, Wheeler JL, et al. Feasibility and acceptability to patients of a longitudinal system for evaluating cancer-related symptoms and quality-of-life: pilot study of an e/ Tablet data-collection system in academic oncology. J Pain Symptom Manage 2009;37:1027-38.

27 Berry DL, Trigg LJ, Lober WB, et al. Computerized symptom and quality-of-life assessment for patients with cancer part I: development and pilot testing. Oncol Nurs Forum 2004;31: E75-83.

28 Fromme EK, Kenworthy-Heinige T, Hribar M. Developing an easy-to-use tablet computer application for assessing patient-reported outcomes in patients with cancer. Support Care Cancer 2011;19:815-22.

29 Hachizuka M, Yoshiuchi K, Yamamoto Y, et al. Development of a personal digital assistant (PDA) system to collect symptom information from home hospice patients. J Palliat Med 2010;13:647-51.

30 Huang H-Y, Wilkie DJ, Zong S-P, et al. Developing a computerized data collection and decision support system for cancer pain management. Comput Inform Nurs 2003;21:206-17.

31 Kallen MA, Yang D, Haas N. A technical solution to improving palliative and hospice care. Support Care Cancer 2012;20:167-74.

32 Kearney N, Kidd L, Miller M, et al. Utilising handheld computers to monitor and support patients receiving chemotherapy: results of a UK-based feasibility study. Support Care Cancer 2006;14:742-52.

33 Lind L, Karlsson D, Fridlund B. Digital pens and pain diaries in palliative home health care: professional caregivers' experiences. Med Inform Internet Med 2007;32: 287-96.

34 Lind L, Karlsson D, Fridlund B. Patients' use of digital pens for pain assessment in advanced palliative home healthcare. Int J Med Inform 2008;77:129-36.

35 Lind L. Evaluation of the use of digital pens for pain assessment in palliative home healthcare. Stud Health Technol Inform 2008;136:101-06.

36 Mark TL, Johnson G, Fortner B, et al. The benefits and challenges of using computer-assisted symptom assessments in oncology clinics: results of a qualitative assessment. Technol Cancer Res Treat 2008;7:401-6.

37 Wilkie DJ, Huang HY, Berry DL, et al. Cancer symptom control: feasibility of a tailored, interactive computerized program for patients. Fam Community Health 2001;24:48-62.

38 Wilkie DJ, Judge MK, Berry DL, et al. Usability of a computerized PAINReportIt in the general public with pain and people with cancer pain. J Pain Symptom Manage 2003;25:213-24.

39 Kroenke K, Spitzer RL, Williams JB. The PHQ-9: validity of a brief depression severity measure. J Gen Intern Med 2001;16: 606-13.

40 Cleeland CS. Measurement of pain by subjective report. In: Chapman CR, Loeser JD, eds. Issues in Pain Measurement. New York: Raven Press, 1989: 391-403.

41 Brown V, Sitzia J, Richardson A, et al. The development of the Chemotherapy Symptom Assessment Scale (C-SAS): a scale for the routine clinical assessment of the symptom experiences of patients receiving cytotoxic chemotherapy. Int J Nurs Stud 2001;38:497-510.

42 Aaronson NK, Cull A, Kaasa S, et al. The European Organization of Research and Treatment of Cancer (EORTC) 
modular approach to quality of life assessment in oncology: an update. 2nd edn. New York: Raven Press, 1996.

43 Taphoorn MJ, Claassens L, Aaronson NK, et al. An international validation study of the EORTC brain cancer module (EORTC QLQ-BN20) for assessing health-related quality of life and symptoms in brain cancer patients. Eur J Cancer 2010;46:1033-40.

44 EuroQoL Group. Euroqol-a new facility for the measurement of health-related quality of life. Health Policy 1990;16: 199-208.

45 Fainsinger RL, Nekolaichuk CL. A'TNM' classification system for cancer pain: the Edmonton Classification System for Cancer Pain (ECS-CP). Support Care Cancer 2008;16: 547-55.

46 Cleeland CS, Mendoza TR, Wang XS, et al. Assessing symptom distress in cancer: The M. D. Anderson Symptom Inventory. Cancer 2000;89:1634-46.

47 Schwartz AL. The Schwartz Cancer Fatigue Scale: testing reliability and validity. Oncol Nurs Forum 1998;25:711-7.
48 Detsky AS, McLaughlin JR, Baker JP, et al. What is subjective global assessment of nutritional status? J Parenter Enteral Nutr 1987;11:8-13.

49 Aaronson NK, Cull A, Kaasa S, et al. The European Organization of Research and Treatment of Cancer (EORTC) modular approach to quality of life assessment in oncology: an update. 2nd edn. New York: Raven Press, 1996:179-89.

50 Fraass BA, Moran JM. Quality, technology and outcomes: evolution and evaluation of new treatments and or new technology. Semin Radiat Oncol 2012;22:3-10.

51 Johansen MA, Henriksen E, Berntsen G, et al. Electronic symptom reporting by patients: a literature review. Stud Health Technol Inform 2011;169:13-17.

52 Hølen JC, Hjermstad MJ, Loge JH, et al. Pain assessment tools: is the content appropriate for use in palliative care? J Pain Symptom Manage 2006;32:567-80.

53 Melzack R. The short-form McGill Pain Questionnaire. Pain 1987;30:191-7.

54 Hjermstad M, Haugen DF, Bennett M, et al. Pain assessment tools in palliative cancer care. New York: Springer, 2012:71-94. 